\section{Histopathology of the Skin}

Walter J. Lever, M.D. Third edition. Pp. vii + 653 with 320 illustrations. London: Pitman Medical. Philadelphia: J. B. Myincott. 1961. £6.

It seems almost presumptuous for a dermatologist to review the new edition of Lever's book, so used is one to its being an authoritative guide in the histopathology of the skin. Here is Lever in an up-to-date, more valuable form, preserving intact the virtues of the earlier editions.

The general classification used by the author is under the headings of congenital, non-infectious vesicular and bullous diseases, non-infectious inflammatory diseases, drug eruptions, degenerative diseases, diseases caused by bacteria, fungi, protozoa and viruses, metabolic diseases, tumours and the lymphoma and myelosis group. It is, therefore, easy to follow and explore.

In this third edition, seven years after the second, much has been rewritten. Emphasis is laid on the developing techniques of histochemistry and electron microscopy. Several newly recognized entities of great interest to dermatologists-e.g. sub-corneal pustulosis and kerato-acanthoma-have now been assimilated into the book. A few diseases previously recognized but not discussed by Lever have now been included, e.g. lethal midline granuloma of the face.

There is, as before, an abundance of good black and white photographs, but the text is perhaps more important, providing a clear dissertation on the histological features of every feature under discussion, with brief notes on the clinical appearance; the attention paid to differential (histological) diagnosis is especially valuable. Unobtrusively the reader is given an account in which fact and theory, experimental and clinical findings are given their due share. The style is of consistent clarity.

There are excellent introductory chapters on techniques, embryology and the histology of normal skin. The book is rounded off by a useful glossary and a good index. One of the greatest merits of this book is the provision of reasonably full and up-to-date lists of references following each chapter; lists which are not narrowly confined to American sources but which draw upon the dermatological literature of the world.

This book, the new edition no less than the old, is indispensable for the dermatologist and for any pathologist dealing with dermatological material.

\section{An Atlas of Histopathology of the Skin}

G. H. Percival, G. L. Montgomery and T. C. Dopds. Second edition. Pp. xi + 491. 525 photographs in colour. Edinburgh and London: E. \& S. Livingstone. 1962. £6 ros.

This book is essentially an Atlas. With this second edition, five years after the first, a text has been written to link the photographs, some contents have been included which were not in the first edition. and there are some new illustrations.

It is well produced and the colour is undoubtedly a help for the student of histology, especially when looked at as the authors advocate in artificial (filament lamp) light.

There is a short guide to terminology and a good index. In the reviewer's opinion, however, the text suffers from the lack of a bibliography and from its classification of the subject matter; the authors say $\because$. the subject has been arranged in groups according to the component part of the skin which shows the most structural alteration ... the salient histological changes which occur in the tissues in each group can be easily contrasted and this would seem to compensate for the fact that conditions which have no etiological relationship are to be found in close proximity'. Scabies under this scheme is grouped under diseases affecting the epidermis, and is given only a cross reference in the section on diseases caused by animal parasites. How ever, this classification has clearly been given much thought by the authors, and any method has its dra backs; here the good index mitigates any inconvenience.

In their brief linking text the authors contrive well give a brief account of morphology and histology withot straying into clinical uncertainties. Many dermatologis however, would consider unsatisfactory an account mycosis fungoids not mentioning by name the Pautrier micro-abscesses, of rosacea-like tuberculide under the heading of sarcoidosis and without further explanation of its already misleading name, of bullous diseases witb the only mention of pemphigoid a casual one under the heading of dermatitis herpetiformis. Some new and now fairly well recognized entities are included-e.g? alopecia mucinosa and elastoma perforans verruciforn -but others well established are not-e.g. granular celled myoblastoma and Jessner's lymphocytic infiltration of the skin.

Though not comprehensive or authoritative this book is valuable for the excellent illustrations, and would tef best used as an introduction to the subject or in cons. junction with a reliable textbook of dermatology.

Fingerprint, Palms and Soles; An Introduction to Dermatoglyphics

H. Cummins, Ph.D., and C. Midlo, m.D. Pp. xi 319, illustrated. New York: Dover Books. I $96 \$$ $\gg 1.95$.

One's first impression on reading this book is surprise that so much can be written on the subject-yetothe preface says this is an introduction to the subjes dermatoglyphics and that it does not aim to be a prines to those engaged in its chief practical application, i.e. criminology.

There is, none the less a large bibliography for the reader wishing to go into these aspects more thoroughl $\overline{8}$.

The work is divided into three parts. The first deads with the historical background, and much of this $\frac{\mathcal{O}}{\Phi s}$ fascinating, though presented somewhat diffusely. The possible significance for instance of fingerprints pottery is discussed and that of design suggestim fingerprints in burial chambers. The development $\theta$ the scientific aspects is dealt with in detail.

Part II deals extensively with the minutiæ of methods description and classification.

Part III deals with 'the more fundamental biologic phases of dermatoglyphics'. This surveys comparatife work-humans and other primates-, racial status, work in embryology, genetics and in possible links wifg various diseases.

There is a supplement consisting of anecdotes on the identification of criminals and exoneration of the innocent which seems curiously out of keeping with the rest of the book. The index is very good.

The book is written in American, which is a language in its own right and should not be judged by standaras applied to English; but the American here is both turgid and diffuse, and the style in general leaves mud to be desired-e.g. "The student of dermatoglyphides will not fall into the error of presuming that dermato glyphic features now provide ready answers for re fractory questions in the history of races, particulaty when he sees that attacks from many quarters have faile to yield a completely knit scheme of the affinity races'.

Its main value to the general medical reader wout appear to be the revelation of a great body of wor 
some of which may be relevant to various lines of research, for example on racial factors in disease.

The binding, and the quality of the paper and printing is very good, particularly, as the publishers point out, for a paper back at its relatively low price.

\section{Fluorescent Protein Tracing}

Edited by R. C. NaIRN, M.D., PH.D. Pp. viii +280 , illustrated. Edinburgh and London: E. \& S. Livingstone. 1962. 425 .

This book is primarily intended for those who are working in the field of fluorescent antibodies. The opening chapters describe in detail the physical and chemical properties of fluorochromes. These substances are conjugated to proteins for study, and the methods for doing this, together with the purification of the conjugates, are given. Physical and chemical properties of the conjugates are described.

The next chapter is devoted to practical details of microscopic equipment required for fluorescent antibody work and information about photomicrography. General considerations on histological methods of study and the various pitfalls encountered, particularly with nonspecific staining, are described in detail.

The latter half of the book makes fascinating reading. Methods for immunological tracing of specific bacteria and other infecting agents, namely, protozoa, helminths, fungi, viruses and rickettsiæ, are discussed, and these are accompanied by extremely good photographs, some of them in colour.

In some virus conditions it has been possible to trace the actual site of production of the antibody within the cell.

However, the author points out that in many conditions in bacteriological and virological work where existing methods are adequate fluorescent microscopy would not be indicated, but where minute amounts of antibody are present it is of undoubted value.

Native tissue antigens have also been studied and it is of considerable interest that malignant tumours lose the ability to show fluorescence with the organ specific antisera. Further exploration into the possibilities of this method of examining tumours is obviously imperative.

This is a very useful book. The author has gone to great trouble to point out the technical snags which are likely to arise. The potentialities of this type of investigation are almost limitless and a book of this kind is of great value to anybody wishing to embark on it.

The bibliography at the end contains 680 references.

\section{The Anatomy of the Cerebro-Spinal Fluid}

J. W. Miller, M.D., D.sC., and D. H. M. WollaM, M.A., M.D., M.R.C.P. Pp. viii + I 51 , illustrated. London: Oxford University Press. I $962.50 s$.

This book is an up-to-date survey of existing knowledge of the cerebrospinal fluid, its formation and circulation. The text is clear and concise throughout and there are many well-chosen diagrams and photographs.

The first chapter is devoted to historical aspects, which, in spite of its necessary brevity, succeeds in being a comprehensive survey from the time of Hippocrates. The anatomy of the ventricular system is outlined and the cavity dimensions presented in tabular form. The author's experience in this field is much in evidence in the chapters on the choroid plexuses and pia mater, which are undoubtedly the highlights of this book. The photomicrographs illustrating the epithelial cells of the choroid plexuses are particularly helpful and later in the book the subdivision of the pia mater into the intima pia and epi-pial tissue is illustrated. It is un- fortunate that a little more space could not be devoted to the cerebrospinal fluid itself, but this is to a large extent compensated for by numerous references in the text.

Postgraduate students, particularly those with an interest in neurology and kindred subjects, will find the book useful and, furthermore, pre-clinical students should benefit from the clear, concise account of the ventricular system and choroid plexuses.

\section{Thalassemia-A Survey of Some Aspects}

ROBIN M. BANNERMAN, M.A., D.M., M.R.C.P. Modern medical monographs. Pp. vi $+\mathbf{r 3 8}^{8}$ illustrated. New York and London: Grune \& Stratton. 196r. 46s.

This manuscript won the first prize in a competition for Modern Medical Monographs, very deservedly, and gives a lucid, concise and yet full account of the information on Thalassemia. As the author rightly points out, these conditions present 'a number of puzzles which are of importance and interest to the general physician, the hæmatologist, the pædiatrician, the biochemist, the geneticist, the epidemiologist, and perhaps even the geographer and historian'. In spite of the wide ramifications of the problem, the author succeeds in giving a full picture.

The book starts with a brief picture of historical background, followed by a chapter on the genetics of the normal hæmoglobins, their distribution and incidence. The third chapter gives the main clinical features with some illustrating case notes, and chapters 4 and 5 the hæmatological findings and points of differential diagnosis. Chapters 6 and 7 deal with the mechanism and processes of hæmoglobin synthesis and various disorderso of hæmoglobin synthesis, with particular reference to ineffective erythropœisis. These chapters lead up to $\leq$ chapter 8, dealing with the iron and hæmoglobin metabolism in Thalassemia. The book is concluded by a stimulating short chapter on the theories of pathogenesis and future possible investigations into the nature of this disease. There are 375 references, with full titles.

The book is eminently readable and highly recommended. It will be only after several readings that the richness of information in the deceptively simple sentences will be appreciated.

\section{Progress in Hæmatology Vol. III}

Edited by Leandro M. Tocantins, M.D. Pp ix + 384, illustrated. New York and London: Grune and Stratton. 1962. \$16.50.

This third volume following the previous two, spaced at three-year intervals, gives some indication of the rapid advancements which have been made in hæmatology. There are 14 independent contributions by 25 authors, the majority from the U.S.A. The style of the book follows its predecessors; again the references are not listed uniformly, in some they are in numerical order as in the text and in others in alphabetical order.

With such a work only certain special aspects of hæmatology can be dealt with and there is no attempt at comprehension. Some of the material is academic, e.g. the section on the aetiology of avain leukemia by J. W. Beard.

Hæmatology has been considered in association with other disciplines. The chapter on malignant lymphoma deals chiefly with two methods of differentiation, namely histological and biochemical. The biochemical approach has been well catered for. There are three sections dealing with different aspects of altered plasma . 